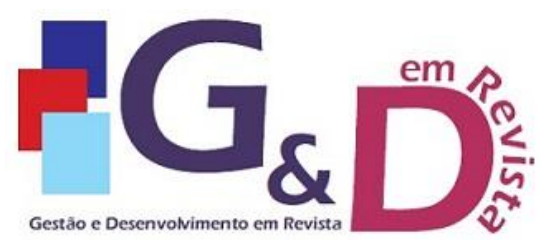

Gestão e Desenvolvimento em Revista

V. 7, N. 1, jan-jun/2021, p. 15-36.

ISSN online: $2446-8738$

Artigo recebido em: 20/05/2021

Artigo aprovado em: 12/07/2021

\title{
AGRONEGÓCIO E DESENVOLVIMENTO ECONÔMICO: UM RESGATE HISTÓRICO DA EVOLUÇÃO DA ECONOMIA AGRÍCOLA PARANAENSE
}

\author{
Cármem Ozana de Melo \\ Doutora em Agronomia/Energia na Agricultura pela Universidade Estadual Paulista - UNESP \\ Júlio de Mesquita Filho. Atualmente é professoa associada da Universidade Estadual do Oeste do \\ Paraná - UNIOESTE. \\ E-mail: carmem.melo@unioeste.br
}

\section{Resumo:}

$\mathrm{Na}$ literatura econômica, os trabalhos que abordam a questão do desenvolvimento, sobretudo nas primeiras fases desse processo, realçam a importância da agricultura. Na história econômica do Brasil e do estado do Paraná tal fato também é percebido, de modo que, resgatar a história dessa evolução se torna interessante, na medida em que permite visualizar a contribuição da agricultura e do agronegócio para o desenvolvimento, dinamismo e configuração das atividades econômicas e sociais no estado. Diante disso, este artigo tem como objetivo apresentar uma retrospectiva da evolução agrícola do estado, mostrando sua importância e reflexos na conformação de sua economia. Para tanto, é apresentado de forma sucinta uma periodização da história econômica paranaense, o que permitiu caracterizar a forma como o processo se configurou no estado.

Palavras-chave: Agronegócio - Desenvolvimento econômico - Desenvolvimento regional Agricultura

\begin{abstract}
:
In the economic literature, works that address the issue of development, especially in the early stages of the process, highlight the importance of agriculture. In the economic history of Brazil and the state of Paraná, this fact is also perceived, so that retrieving the history of this evolution becomes interesting, as it allows visualizing the contribution of agriculture and agribusiness to the development, dynamism and configuration of economic and social activities in the state. Therefore, this article aims to present a retrospective of the agricultural evolution of the state, showing its importance and reflexes in the shaping of its economy. For this purpose, it is presented in a succinct way a periodization of the economic history of Paraná, which changes to characterize the way the process was configured in the state.
\end{abstract}

Key words: Agribusiness - Economic development - Regional development - Agriculture 


\section{Introdução}

Destaca-se, na literatura econômica, a importância da agricultura para 0 desenvolvimento econômico do país. É, então, interessante observar que os trabalhos que abordam a questão do desenvolvimento, sobretudo nas primeiras fases desse processo, enfatizam o papel agricultura.

Neste sentido, mesmo que a partir dos anos 1950, os países subdesenvolvidos tenham dado especial atenção à idealização de planos que limitaram-se, basicamente, a um processo de industrialização intensiva, que se configurava como sinônimo de desenvolvimento econômico, o setor agrícola aparece como crucial para o alcance de metas traçadas, com efeitos indutores nos demais setores econômicos.

No Paraná, o processo de colonização e a forma como foi inserido na economia nacional são responsáveis por muitas de suas presentes feições. A história econômica do estado se confunde com a evolução de sua economia agrícola. Assim, o crescimento e as alterações da estrutura produtiva paranaense, com reflexos econômicos e sociais importantes, estiveram ligados de algum modo ao setor agropecuário. Apesar da perda da supremacia da agricultura na economia do estado, deixando de ser eminentemente agrícola e passando a apresentar peso o setor industrial, a configuração espacial das atividades industriais do estado encontra-se de alguma forma atrelada ao setor primário, quer pelos impactos sociais gerados, especialmente no que diz respeito à migração, quer pela industrialização do próprio setor, ao se modernizar tanto no uso de fatores de produção de origem industrial (e se constituir, portanto, em demandante de produtos industriais) quanto no processo de produção e comercialização. Este encadeamento da agropecuária com segmentos à montante e à jusante configurou-se na constituição e consolidação do agronegócio no Estado.

Desse modo, o agronegócio torna-se importante especialmente para algumas regiões do estado que, até meados da década de 1980 se caracterizavam por serem essencialmente agrícolas. A partir de então, a indústria começa e se consolidar e ter sua dinâmica orientada fundamentalmente pelo comportamento do agronegócio.

Por outro lado, há de se registrar que, especialmente na região metropolitana de Curitiba, ocorre o crescimento de outros setores industriais não 
ligados ao agronegócio. Contudo, a conformação deste setor tem, tem certa medida, alguma relação com os impactos gerais causados pelas alterações do setor agrícola, principalmente ao receber grandes fluxos migratórios provindo principalmente das regiões que sofriam alterações em sua agricultura.

Assim, ocorreram importantes transformações na base produtiva do estado do Paraná. Neste contexto, pretende-se, neste artigo, mostrar a evolução agrícola do estado e seus reflexos na conformação da economia do estado. Para atingir tal propósito apresenta-se de forma sucinta uma periodização da história econômica paranaense, o que pode contribuir para a compreensão do tema.

Além dessa introdução, este trabalho apresenta, na sequência, algumas discussões acerca da literatura que relaciona agricultura e desenvolvimento econômico. Em seguida, faz-se um relato sucinto dos ciclos da economia agrícola paranaense. Abre-se um item específico para o processo da modernização agrícola e o agronegócio paranaense. Por último, são feitas as considerações finais.

\section{Agricultura e desenvolvimento econômico}

O período pós-guerra tem-se caracterizado por uma busca contínua do processo de desenvolvimento econômico. Nos anos 1950, os países subdesenvolvidos deram especial atenção à idealização de planos que limitaram-se, basicamente, a um processo de industrialização intensiva, que se configurava como sinônimo do desenvolvimento econômico.

Neste contexto, o setor agrícola é referido como tendo certas funções a desempenhar com o objetivo de dar suporte ao processo de industrialização, normalmente identificado com o processo de crescimento e desenvolvimento econômico. Nesta concepção, o desenvolvimento agrícola é interpretado como um passo intermediário para a realização do desenvolvimento industrial e crescimento econômico.

Apesar de os trabalhos de Rostow, Lewis, Fei-Ranis, Jorgenson, além de outros, terem enfatizado a importância da agricultura, Albuquerque e Nicol (1987) apontam que o artigo de Johnston e Mellor (datado de 1961) é considerado um marco de referência. No estudo é ressaltado que, através do aumento da produção e da produtividade, a agricultura e, por extensão, o setor rural, poderiam oferecer 
contribuições ao processo de crescimento econômico. São mencionados cinco papéis básicos: a) Liberação de mão-de-obra para o setor industrial; b) fornecimento de produtos alimentícios e matérias-primas; c) transferência de capital; d) ampliação da disponibilidade de divisas; e) demanda por produtos industrializados: o setor agrícola deveria gerar demanda por produtos manufaturados, intensificando a relação comercial entre o setor agrícola e o industrial (Albuquerque e Nicol, 1987).

Segundo Albuquerque e Nicol (1987), apesar de deficiências estruturais, o setor agrícola brasileiro desempenhou as funções mencionadas, criando condições para o desenvolvimento econômico global e apoio ao crescimento do setor industrial. No mesmo sentido, Accarini (1987) ressalta que as cinco funções atribuídas ao setor rural no processo de desenvolvimento econômico é uma colocação de caráter geral, aproximando-se, contudo, do verificado no Brasil. Segundo o autor, a partir da metade do século XIX se registrava em várias regiões um incipiente processo industrial, cuja implantação e desenvolvimento estiveram ligados, nas suas origens, à produção de café, açúcar, cacau, tabaco, couros e peles, mate e outros produtos exportáveis.

De acordo com Gonçalves (1999) a análise da agricultura na abordagem tradicional não rompe com os limites da agropecuária e baseia-se na capacidade setorial de dar sustentação à transformação da economia, desde que fossem cumpridas adequadamente suas funções no processo de desenvolvimento. Argumenta, ademais, que a visão tradicional tem sido transportada para o caso brasileiro sem questionamento do pressuposto inerente à concepção adotada quanto à setorização da economia. $\mathrm{O}$ autor continua, afirmando que a abordagem tradicional não dá conta da compreensão do processo de transformação da agricultura, ao apegar-se à tese da tendência à insignificância que reforça a perspectiva de uma importância marginal para o setor.

Assim, Pinho e Vasconcelos (2003), expõem que os estudiosos do desenvolvimento da agricultura propuseram modelos de ação que procuraram enfatizar a possibilidade de aumentar a produtividade dos fatores tradicionais, pela introdução de modificações tecnológicas. Tal necessidade de modernização torna o setor agrícola cada vez mais dependente dos demais setores da economia. Segundo os autores: 
Considerando esta dependência e analisando a reestruturação agrícola é que foi apresentado, em 1957, pelos economistas americanos Ray Goldberg e John H. Davis o termo agribusiness (...). Dentro desse significado é que, modernamente, deve ser analisado o papel da atividade agrícola no desenvolvimento econômico (Pinho e Vasconcelos, 2003, p. 515).

Neste sentido, partindo do pressuposto de que o meio rural brasileiro se urbanizou nas últimas duas décadas, como resultado, de um lado, do processo de industrialização da agricultura e, de outro, do transbordamento do mundo urbano naquele espaço que tradicionalmente era definido como rural, a agricultura - que antes podia ser caracterizada como um setor relativamente autárquico, com seu próprio mercado de trabalho e equilíbrio interno, se integrou no restante da economia a ponto de não poder mais ser separada dos setores que the fornecem insumos e/ou compram seus produtos (Graziano da Silva, 1997).

Como afirma Gonçalves (1999), em síntese, a agricultura atualmente não tem função marginal nem passiva no desenvolvimento econômico. Ao contrário, trata-se de um setor estratégico nesse processo como amplificador da acumulação capitalista. O autor afirma, ainda, que "o desenvolvimento capitalista da agricultura, entretanto, não se realiza calcado apenas em medidas rurais, ao contrário, como uma indústria de base biológica, os instrumentos fundamentais na determinação do dinamismo são elementos de política industrial verticalizada" (Gonçalves, 1999, p. 33).

Com isso, emergem novos atores sociais e novas funções são demandadas, emergindo a questão da multifuncionalidade da agricultura. De acordo com Cazella (2003), a multifuncionalidade agrícola tem sido interpretada como aspecto fundamental de um modelo de desenvolvimento agrícola e rural construído à margem da Política Agrícola Comum (PAC), sendo genericamente definida como o conjunto das contribuições da agricultura a um desenvolvimento econômico e social considerado na sua unidade. Dessa forma, tem sido associada à segurança alimentar (garantia da qualidade e origem dos produtos, além da garantia de um potencial produtivo), à manutenção do território (preservação das características paisagísticas e do quadro de vida), à proteção do meio ambiente, à salvaguarda do capital cultural e à garantia de um tecido econômico e social rural pela diversificação das atividades. 


\section{A economia agrícola paranaense}

$\mathrm{Na}$ história econômica paranaense, da ocupação à modernização e agroindustrialização, podem ser mencionados, de forma resumida, os seguintes ciclos: ocupação e desenvolvimento de economias de bases extrativistas; passagem da economia de base extrativista para a cafeeira; modernização agrícola.

De acordo com Souza (2000, p.10), "o processo de ocupação e desenvolvimento de atividades econômicas no estado do Paraná ocorreu através de ciclos descontínuos, sendo que cada um deles aproveita pouco do precedente. (...) A formação histórica e econômica paranaense apresenta ciclos distintos e não relacionados entre si".

O mesmo autor afirma que a ocupação e exploração econômica do Paraná iniciou-se no século XVI, basicamente através de três frentes, oriundas de diferentes direções: a primeira, de origem portuguesa, avançou pelo litoral à procura do ouro de aluvião formando o primeiro núcleo estável, Paranaguá. A segunda, organizada pelos espanhóis, entrou pela região oeste. A terceira, as bandeiras, foi a expansão exploradora que partiu de São Paulo (Souza, 2000).

No período inicial, colonos e jesuítas espanhóis povoaram Paranaguá e Curitiba, tendo sido a primeira experiência de um sistema de agricultura baseada na propriedade coletiva de terra e produção. Porém, essa experiência teve caráter limitado no tempo e no espaço, porque entrou em colisão com a terceira frente exploradora que visava capturar índios pacificados e catequizados para vendê-los como escravos, sem, contudo, desenvolver atividade econômica que significasse ocupação permanente do território (Souza, 2000; Ambiente Brasil, 2005).

Com a descoberta de ouro, portugueses foram atraídos. A atividade de exploração do ouro chegou a possuir alguma importância. Esse ciclo teve sua expressão máxima no início do século XVII e contribuiu para a formação de muitos arraiais que eram mantidos por pequena agricultura. Essa pequena economia de subsistência permaneceu, por quase meio século, concentrada no planalto (Ambiente Brasil, 2005; Souza, 2000). Contudo, de acordo com Padis (1981) embora esta atividade tenha sido a primeira causa de ocupação, determinando o aparecimento de núcleos urbanos, a dimensão das descobertas e o valor das extrações não tiveram importância significativa. 
A descoberta de ouro em Minas Gerais amenizou a exploração no Paraná. Com isso, mesmo não se extinguindo completamente as atividades de mineração e o cultivo de mantimentos e a exploração de erva-mate para auto-consumo, ganhou destaque nesse momento a criação e comercialização de gado. A pecuária passou a ser atividade predominante, sendo que as pessoas que possuíam mais recursos, adquiriam gado no sul do país e o revendia em Sorocaba (SP). A passagem de tropas vindas de Viamão (RS) para Sorocaba (SP) propiciaram o tropeirismo no Paraná. Dessa forma, a ocupação do território paranaense ampliou-se, estimulando, junto às rotas e aos melhores pastos, novos povoamentos que, com o passar dos tempos tornaram-se cidades (Rio Negro, Campo do Tenente, Lapa, Porto Amazonas, Palmeira, Ponta Grossa, Castro, Piraí do Sul, Jaguariaíva e Sengés) (Ambiente Brasil, 2005; Souza, 2000). Com o esgotamento da exploração de ouro em Minas Gerais, o tropeirismo ainda teve certo fôlego com a expansão cafeeira. Contudo, a concorrência imposta pela criação de estradas de ferro e a crise que se seguiu ao declínio da exploração aurífera, o ciclo do tropeirismo caiu em declíneo.

Assim, a economia paranaense volta à estagnação e a agricultura de subsistência passa a ser novamente a atividade principal, porém expandindo-se em direção à região oeste do estado (Palmas e Guarapuava). Aos poucos, a extração e o preparo da erva-mate começa a surgir como uma atividade de importância econômica, sobretudo após 1722, quando se permitiu o comércio com os mercados platinos (Buenos Aires e Montevidéu) e Chile. A partir do momento em que esta atividade recebe impulso do mercado externo e torna-se lucrativa, empresários assumem o comando das atividades e os pequenos agricultores ficam subordinados a esse comando. A atividade ervateira atingiu o apogeu em meados da segunda década do século vinte e estagna-se a partir daí, graças à participação crescente de outros produtos na economia local: o café e a madeira (Souza, 2000).

Paralelamente à atividade ervateira, no final do século dezenove, a madeira passa a ser explorada comercialmente devido aos estímulos internos (crescimento da economia brasileira, principalmente atribuído à expansão da cultura do café) e externos (começo das exportações para outros países).

Segundo Cancian (1977), no século XIX, enquanto ganhava importância a produção cafeeira no estado de São Paulo, o Paraná tinha sua economia e sociedade baseadas na atividade pastoril, na extração e indústria da erva mate, uma 
incipiente agricultura de subsistência e, no final do século, a madeira começa a ter expressão.

Entretanto, Souza (2000) argumenta que, da mesma forma que a extração da erva-mate, com as possibilidades de crescimento e de se tornar um ramo lucrativo, a atividade madeireira atraiu a presença de capitais estrangeiros, principalmente de origem americana e inglesa. Contudo, segundo Souza (2000, p. 16), "a economia madeireira não foi completamente absorvida pelo capital externo, permanecendo um setor madeireiro local, industrial e exportador importante".

De acordo com Magalhães Filho (1996, citado por Souza, 2000), os núcleos de imigrantes de origem europeia desenvolveram, nesse período, uma agricultura de subsistência com pequenos excedentes comercializáveis. Diversificaram a produção agrícola, incrementaram a produção de suínos, de leite e de laticínios. Entretanto, a estrutura geral da economia paranaense modificou-se pouco, permanecendo dependente das atividades primário-exportadoras.

O ciclo do café provocou impactos importantes na economia agrícola do Paraná. Oriundo de terras paulistas, a cultura do café rapidamente se expandiu na segunda metade do século dezenove e atingiu a região nordeste do estado, o chamado 'Norte Velho', e espalhou-pela região norte, atingindo as margens do rio Paraná. Até o final da Segunda Guerra Mundial o Paraná não se apresentava como um grande produtor de café.

De acordo com Cancian (1977), no início do século XX a cafeicultura começou a se tornar importante no norte do estado, sendo uma opção para o Paraná se manter ligado à exportação. O governo passou a proteger a atividade com os meios de que dispunha, dando surgimento ao Paraná Novo. A construção de um ramal ferroviário, ligando Jaguariaíva a Jacarezinho, foi a primeira tentativa para estimular a exportação da produção pelo porto de Paranaguá, antes feita através do porto de Santos, não sendo, contudo bem sucedida. Duas outras medidas foram tomadas, estimuladas pelo governo do estado: criação de empresas particulares que passaram a concorrer com as paulistas nas regiões produtoras e diminuição das taxas de exportação no porto de Paranaguá. Contudo, as medidas surtiram pouco efeito, com o estado de São Paulo continuando seu processo de apropriação dos excedentes gerados. Apesar disso, a expansão da atividade cafeeira cresceu em menos de uma década. 
Com a expansão da área cultivada de café e de outras lavouras a ela associada, nas décadas de 1940 e 1950, a consequência foi, além do crescimento populacional, a implantação de um setor comercial voltado para as atividades secundárias e terciárias de transporte, beneficiamento e comercialização que a produção demandava, além de outros serviços que se fizeram necessários com a consolidação econômica da região. Tudo isso se associou à conjuntura internacional favorável.

Contudo, depois desse momento, passa-se a verificar um período de desalento que seu deu, segundo Souza (2000, p.21), "em virtude de grandes quedas da produção, da renda e das receitas estaduais, em função das adversidades climáticas (...) e do aumento da demanda de serviços públicos nas regiões recémocupadas". Ademais, nos anos posteriores, outros aspectos contribuíram para colocar a economia cafeeira em crise: ocorrência de geadas em 1963, 1964, 1966 e 1969; a política de erradicação de cafezais, com a finalidade de diminuir a produção nacional; o desenvolvimento de um novo produto de aceitação internacional, a soja; o receio da ocorrência de novas geadas (Wachowicz, 1995, citado por Souza, 2000).

Os efeitos da geada causaram impacto de grande proporção, de modo que os produtores de café, não estando mais dispostos a ficar expostos a perdas intermitentes ocasionadas por este fenômeno climático resolveram, no início de forma paulatina e posteriormente de forma acelerada, dar prioridade a outros produtos como a soja, trigo e exploração pecuária.

Neste contexto, com o incremento da política de erradicação dos cafezais adotada entre 1965 e 1967, o Paraná ingressa na década de 1970 apresentando uma expansão rápida do cultivo de outros produtos. Essas medidas fizeram parte de uma política econômica de caráter mais amplo, geradas a partir de 1967 e que passam a privilegiar um tipo de agricultura de caráter empresarial. Políticas de crédito e de subsídios foram criadas com a finalidade de ampliar as possibilidades dos produtores rurais na aquisição de máquinas e insumos modernos. Assim, a economia paranaense sofreu uma série de transformações importantes, inserindo-se no contexto da modernização da agricultura.

De acordo com Brum (1988), o Paraná, após a Segunda Guerra Mundial sai do seu marasmo e torna-se um dos estados mais dinâmicos do país. Esta mudança decorre fundamentalmente da transformação operada no setor agrícola. De uma 
agricultura tradicional, rotineira e voltada para a subsistência, o estado passa a contar com uma agricultura mercantil, dinâmica, diversificada e moderna. $O$ caráter mercantil, dinâmico e diversificado ocorre com a colonização das terras do norte do estado, enquanto o fenômeno da modernização da agricultura paranaense vai se processando, principalmente a partir dos anos 1970, inicialmente no sudoeste do estado (Brum, 1988).

\section{A modernização agrícola e o agronegócio}

As transformações ocorridas na agricultura brasileira podem ser percebidas no âmbito da economia paranaense. Pereira (1987) destaca que a estratégia de modernização tecnológica da agricultura brasileira nos anos 1970, causou modificações, especialmente nas regiões ou estados em que a utilização do capital monopolista foi mais acentuada, como o Paraná. Neste sentido, afirma que "a penetração acelerada do capital monopolista na economia e especialmente na agricultura paranaense, dentro do padrão de acumulação adotado, provocou profundas alterações na composição da produção agropecuária e em sua base técnica" (Pereira, 1987, p.169).

No que diz respeito à modificação na composição da produção, aponta como relevante a substituição de culturas, especialmente do grupo 'básicas' por outras, notadamente a soja. O autor chama a atenção para o fato de que a soja constituiu-se o produto central da modernização agropecuária do Centro-Sul, mais especificamente do estado do Paraná, nos anos 1970 (Pereira, 1987).

Nesta mesma linha, de acordo com Brum (1988) a modernização da agricultura paranaense foi alavancada sobretudo pela expansão da cultura da soja, tendo o trigo como lavoura secundária. O mesmo autor continua, afirmando que no espaço de dez anos (1970-1980), a área cultivada com a soja aumentou 695,5\%, passando de uma cultura quase sem importância para o primeiro lugar entre os produtos agrícolas do estado e tornando o Paraná importante produtor nacional de soja. Quanto à cultura do trigo, o autor afirma que esta começou a expandir-se na segunda metade da década de 1960, primeiro de forma relativamente lenta, passando a ter impulso expressivo de 1974 em diante. Contudo, a partir da década de 1980 passou a declinar. A redução da área plantada deveu-se à acentuada 
elevação dos custos de produção e aos grandes riscos que a lavoura de trigo apresentou, gerando insegurança e prejuízos freqüentes aos produtores (Brum, 1988, p.92).

Estudo realizado por Moretto; Rodrigues e Parré, (2002) afirma que as bases da atual estrutura produtiva paranaense foram iniciadas nos anos 1970. Nesse período, ocorreu o aprofundamento da modernização da agricultura e a ampliação do parque agroindustrial, além do surgimento de outras indústrias desvinculadas dessas atividades. No tocante à agropecuária, o processo de modernização foi caracterizado pela concentração fundiária, introdução de culturas mecanizadas e grande transformação tecnológica.

As alterações na base técnica de produção são destacadas por Pereira (1987), dentro das transformações da agricultura paranaense nos anos 1970. O autor afirma que no período 1970/80 ocorre um crescimento de $338,9 \%$ no número de tratores, sendo que na região Oeste do estado observa-se a mais alta taxa, da ordem de $698,4 \%$. No que se refere ao aumento do número de estabelecimentos que passam a utilizar adubos químicos e calcário, os percentuais foram da ordem de $266,9 \%$ e $488,8 \%$ para o estado, havendo diferenças entre as regiões, sendo $145,1 \%$ e $337,7 \%$ para a região Norte e $1.274,7 \%$ e $697,0 \%$ para a região Oeste. No espaço de 10 anos, houve grande aumento no uso de agrotóxicos na agropecuária paranaense, da ordem de 74,1\% (Pereira, 1987).

Nesta mesma linha, segundo Brum (1988), dentre os indicadores da modernização da agricultura no Paraná, três têm destaque especial: a mecanização, o uso de fertilizantes e o crédito rural. Em relação ao crédito rural, o autor expõe que tal programa, a juros favorecidos, implantado a partir de 1965, com o objetivo de modernizar a agropecuária brasileira, criava, ao mesmo tempo, um amplo mercado para a indústria de máquinas, implementos, equipamentos e insumos agrícolas, já implantada a nível nacional, criando ainda condições para sua expansão. No Paraná, no período de 1970 a 1979 o crédito rural apresentou crescimento de cerca de $500 \%$, passando de uma proporção de $37 \%$ para $80 \%$ do valor bruto da produção agropecuária como um todo e para $89,4 \%$ da produção agrícola, revelando a dependência dessas atividades em relação ao crédito rural. $O$ autor continua, afirmando que tais dados ajudam a compreender o choque provocado com a 
redução do volume do crédito rural e a elevação das taxas de juros, em decorrência da retirada dos subsídios, na primeira metade dos anos oitenta (Brum, 1988, p.95).

A esse respeito, Carneiro (2004) afirma que o esgotamento das fontes de financiamento em nível regional representou cerca de $64,5 \%$ no crédito concedido ao Paraná durante os anos 1980. Já na década subseqüente, acontecem períodos de oscilações com um pico em 1994, quando ocorre uma expansão do financiamento de aproximadamente $76 \%$. No entanto, este crescimento não representou uma tendência, e o crédito sofreu uma redução de $59,5 \%$ no ano seguinte.

Os anos 1980 têm sido vistos como uma década marcada por crises e instabilidade econômica, as quais impuseram limites ao desempenho e crescimento da estrutura produtiva brasileira e paranaense. Segundo Rolim (1995, citado por Moretto; Rodrigues e Parré, 2002), a recessão ocorrida nos primeiros anos dessa década não causou grandes prejuízos à economia do Paraná em função do desempenho favorável da agropecuária e de alguns ramos industriais, como o de alimentos e a indústria química, não obstante a profunda crise da indústria da construção civil. A análise setorial mostra que o setor agropecuário, apesar da grande instabilidade das políticas econômicas e das profundas alterações dirigidas a ele, não sofreu danos significativos (Moretto; Rodrigues e Parré, 2002).

De acordo com Rezende e Parré (2003), as mudanças da estrutura produtiva da agricultura paranaense vêm se verificando desde a segunda metade da década de 1980, de forma menos intensa que a observada na década de 1970. Tais mudanças implicaram em dois aspectos: modificações e diversificação na pauta de produção e a incorporação de novas tecnologias de modo a compensar o esgotamento da fronteira agrícola. Os mesmos autores apontam que na década de 1990, as mudanças verificadas na década de 1980 se tornam mais rápidas em decorrência da abertura comercial e da valorização do câmbio.

Segundo Carneiro (2004), o cenário de abertura comercial conjugado a questões relativas ao crédito rural, fez com que houvesse um reordenamento no âmbito estadual, alterando o perfil da produção agrícola, havendo uma participação ascendente de produtos com inserção do mercado internacional, caracterizados pela alta competitividade e maior autonomia em relação ao apoio do governo para plantio 
e comercialização, sendo "nítidas as vantagens das culturas de milho, trigo e, principalmente, soja, em produção e área cultivada".

Neste sentido, Rezende e Parré (2004) afirmam que a atividade agrícola no Paraná passou por um processo de modernização com a finalidade de enfrentar a concorrência internacional, intensificando o deslocamento regional da produção agrícola em direção às regiões que oferecem condições propícias para o desenvolvimento de sistemas produtivos mais competitivos. Com as alterações na pauta dos principais produtos da agricultura paranaense, a soja e o milho foram os que apresentaram melhor desempenho, visto que passaram a ser os mais importantes produtos agrícolas, tanto em termos de produção quanto em área ocupada. Assim, nos anos 1990 observa-se uma expansão das culturas temporárias, em detrimento das culturas permanentes.

O fato de que culturas básicas foram substituídas por outras que têm em seu processo de produção o uso de todo o aparato construído no processo de modernização da agricultura paranaense, teve reflexos sobre o rural. Trata-se, aliás, de uma continuidade do aspecto já destacado por Pereira (1987) relativo às décadas de 1970 e 1980, nas quais houve (de forma mais intensa nos anos 1970, diminuindo a intensidade posteriormente) substituição de culturas, tanto em termos de área plantada quanto em quantidade produzida.

Desse modo, os aspectos da modernização apontados por Brum (1988) e Pereira (1987) têm sequência nos períodos subsequentes, com aumento do número de estabelecimentos que possuíam tratores, colheitadeiras e uso de fertilizantes.

De acordo com a SEAB/DERAL (2003), todo este processo fez com que o Paraná se tornasse o maior produtor de grãos do país, apresentando expressivo crescimento da safra de grãos, ganhos de produtividade e aumento de área plantada, desde o início da década de 1990.

Os resultados da década de 1990 e indicação de continuidade no início dos anos 2000 permitem perceber a consolidação e seguimento dos rumos traçados no começo do processo de modernização agrícola. No estudo de Pereira (1987) é exposta de forma clara a significativa perda de importância de produtos básicos na década de 1970, que foram substituídos especialmente pela soja, importante matéria-prima industrial e de grande aceitação no mercado externo. 
Nesse sentido, Brum (1988) chama a atenção para o fato de que o processo de modernização da agricultura teve uma tendência irreversível. O mesmo autor aponta que, a modernização acarretou ganhos importantes, tais como: "incorporação de novas culturas, avanço tecnológico, dinamização do processo produtivo, expansão do cooperativismo, geração de capital e produção de matérias-primas para a implantação e funcionamento de várias agroindústrias, entre outros" (Brum, 1988, p.96). O autor não deixa de citar, no entanto, que há o lado sombrio desse crescimento, expresso principalmente pelos custos sociais representados pela expulsão de milhares de pequenos produtores rurais.

Nestes termos, Souza (2000, p.25) afirma que "de forma geral, as transformações na base técnica de produção da agricultura paranaense modificaram profundamente a organização social rural e trouxeram consequências sociais importantes". O autor cita as alterações na estrutura fundiária, as alterações na evolução das ocupações agrícolas e nas relações de trabalho no campo, o impulso às as cooperativas a questão da migração e urbanização.

Em relação à estrutura fundiária, segundo a SEAB/DERAL (2003), o Paraná caracteriza-se pela predominância de pequenas propriedades. Intimamente relacionado ao tamanho dos estabelecimentos rurais está a concentração da posse da terra.

Utilizando dados dos Censos Agropecuários do IBGE, estudo realizado por Hoffmann e Ney (2010), permite verificar o que ocorreu com a concentração da propriedade da terra no estado. A Tabela 1 mostra os resultados encontrados pelos autores. Os dados mostram que houve um aumento da concentração da terra no estado, passando de 0,702 no início do período para 0,770 (aumento de 9,69\% no período). 
Tabela 1 - Índice de Gini, percentual de área total correspondentes aos 50\% menores e aos $5 \%$ maiores estabelecimentos rurais e variação no período. Paraná, 1970-2006.

\begin{tabular}{ccccc}
\hline \multirow{2}{*}{ Ano } & Índice de & \multicolumn{2}{|c}{ Percentual da área ocupada } \\
\cline { 3 - 4 } & Gini & $50 \%$ menores & $5 \%$ maiores \\
\hline 1970 & 0,702 & 9,6 & 52,9 \\
1975 & 0,729 & 8,3 & 55,8 \\
1980 & 0,743 & 7,5 & 56,7 \\
1985 & 0,752 & 7,0 & 57,2 \\
$1995 / 96$ & 0,743 & 7,1 & 54,7 \\
2006 & 0,770 & 5,8 & 57,3 \\
\hline Variação (\%) (1970/2006) & 9,69 & $-39,58$ & 8,32 \\
\hline
\end{tabular}

Fonte: Hoffmann e Ney (2010)

$\mathrm{Na}$ Tabela 1 pode-se perceber que, enquanto os pequenos produtores perderam espaço no território paranaense, os grandes ganharam: enquanto houve variação negativa $(-39,58 \%)$ do percentual de área ocupada pelos estabelecimentos menores, a variação foi positiva tanto para os $5 \%$ maiores estabelecimentos rurais, ou seja, os $5 \%$ maiores estabelecimentos passaram a ocupar maior espaço, em detrimento dos menores.

Estes dados sugerem a ligação entre o processo de transformação ocorrido na agricultura desde a década de 1970 e os reflexos advindos de tais mudanças: a redução do número de pessoas no campo, a substituição de culturas e a redução da participação dos pequenos produtores na posse da terra. A relevância deste aspecto revela-se pelo fato de que, como afirmam Boni e Cunha (2002, p. 148):

A concentração da posse da terra determina a estrutura de produção e exerce vigorosa influência sobre a produtividade agrícola, sobre a inovação tecnológica e também sobre o emprego rural, suscitando preocupações dos mais variados níveis, como a busca de uma garantia de níveis mínimos para a população do campo, que a mantenha vinculada a esse campo (Boni e Cunha, 2002, p.148).

No que diz respeito às alterações na evolução das ocupações agrícolas e nas relações de trabalho no campo, ocorreu uma diminuição do regime de parceria e de arrendamento, levando a uma redução do número de trabalhadores residentes nos estabelecimentos rurais.

Segundo Pereira (1987), categorias de produtores e acesso à terra estão intimamente relacionados, de modo que as categorias são importantes na medida em que o acesso à terra se dá a partir de uma delas. 
Assim, o trabalho de Hoffmann e Ney (2010), utilizando os Censos Agropecuários, revela que desde a década de 1970 ocorre o fortalecimento dos proprietários, cuja participação no número de estabelecimentos se eleva de 56,4\% em 1970 para 82,3\% em 2006, enquanto há redução significativa na participação dos arrendatários (12,4\% em 1970 para 7,1\% em 2006) e especialmente dos parceiros, que decresce de 22,2\% em 1970 para 2,2\% em 2006.

Segundo Souza (2000), nos anos 1970 o aparecimento da figura dos trabalhadores volantes temporários no Paraná sofreu influência da valorização das terras em função da política de crédito subsidiado e do fechamento da área de fronteira agrícola. Estes dois fatores contribuíram para acentuar o êxodo rural. O mesmo autor expõe que, nessa época, ocorre também um aumento na categoria dos empregados permanentes e temporários, demonstrando, no caso dos permanentes, que a consolidação e expansão dos estabelecimentos acima de cinqüenta hectares impôs uma especialização ao processo de trabalho agrícola, assim como uma gerência em formas capitalistas modernas.

Quanto aos pequenos produtores, Souza (2000) aponta que aqueles que conseguiram incorporar as inovações tecnológicas o fez reduzindo a necessidade de trabalho familiar, elevando a produtividade do trabalho. Os que não se adequaram ao processo de modernização, passaram a desenvolver outras atividades paralelas à produção para auto-consumo, através do assalariamento de um ou mais membros da família, ou seja, da pluriatividade.

De acordo com Pereira (1987), na década de 1970 o Paraná passou a enfrentar problemas sociais com a liberação de grande contingente de trabalhadores rurais. Ocorreu redução no número de pessoas economicamente ativas no setor agropecuário e, por outro lado, este número foi crescente nos demais setores, significando que parte dos trabalhadores excluídos do setor agropecuário foi absorvida por outros setores produtivos. Contudo, considerando que a economia paranaense estava fundamentada no setor primário, sendo que a maior parte das indústrias eram processadoras de produtos agropecuários e que grande parte das atividades comerciais, de transportes e outras atividades terciárias estavam diretamente ligadas ao setor primário, as transformações no setor agropecuário contribuíram para o aumento de pessoas economicamente ativas em todos os outros setores. 
Outro aspecto ligado ao processo de modernização da agricultura no estado, apontado por Souza (2000), foi o impulso às cooperativas agrícolas, que passaram a participar de forma crescente na comercialização tanto de insumos modernos como nos de origem tradicional, avançando nas questões de armazenamento e industrialização de produtos agrícolas. Contudo, o autor aponta que a retração do crédito no final dos anos setenta implicou que passassem a depender cada vez mais de capitalização própria, surgindo contradições nas relações cooperativas. Entretanto, apesar das contradições, as cooperativas mostraram dinamismo nos anos 1970 e foram importantes no processo, ao estimular e permitir formas de organização da produção, industrialização e comercialização dos produtos agrícolas (Souza, 2000).

Neste contexto, Rezende e Parré (2003) identificaram que os municípios que apresentaram maior grau de desenvolvimento agrícola na década de 1990 foram os que possuíam em seus territórios cooperativas agropecuárias receptoras de cereais e grande parte da indústria esmagadora de soja. Em suas palavras, "os resultados indicam que os municípios mais desenvolvidos no setor agrícola do estado do Paraná são aqueles em que se concentram as cooperativas ou as agroindústrias" (Rezende e Parré, 2003, p.12).

Relacionado intimamente aos aspectos anteriores está a questão da migração e urbanização, com efeitos do processo migratório sobre a formação dos polos urbanos regionais, que serviam de atração para as pessoas que migravam do meio rural.

Uma dimensão dessas tendências pode ser observada através da Tabela 2, que mostra a evolução do crescimento populacional por situação de domicílio nas últimas décadas. Os dados revelam uma progressiva diminuição da população rural e, em contrapartida, um forte crescimento da população com domicílio urbano. Com isso, a população rural diminuiu sua participação na população total de $63,86 \%$ em 1970, para 41,38\% em 1980, 26,64\% em 1991, 18,59\% em 2000 e14,67\% em 2006, com taxas de crescimento negativas em todo o período. 
Tabela 2 - Evolução da população do estado do Paraná, segundo a situação de domicílio - 1970 a 2010.

\begin{tabular}{|c|c|c|c|c|c|c|c|c|c|}
\hline \multirow{2}{*}{ Domicílio } & \multicolumn{5}{|c|}{ População residente } & \multicolumn{4}{|c|}{$\begin{array}{c}\text { Taxa geométrica de crescimento } \\
\text { anual (\%) }\end{array}$} \\
\hline & 1970 & 1980 & 1991 & 2000 & 2010 & $\begin{array}{l}1970- \\
80\end{array}$ & $\begin{array}{c}1980- \\
91\end{array}$ & $\begin{array}{c}1991- \\
00\end{array}$ & $\begin{array}{c}2000- \\
10\end{array}$ \\
\hline Urbano & 2.504 .378 & 4.472 .561 & 6.197 .953 & 7.786 .084 & 8.912 .692 & 5,97 & 3,01 & 2,59 & 1,36 \\
\hline Rural & 4.425 .490 & 3.156 .831 & 2.250 .760 & 1.777 .374 & 1.531 .834 & $-3,32$ & $-3,03$ & $-2,61$ & $-1,40$ \\
\hline Total & 6.929 .868 & 7.629 .392 & 8.448 .713 & 9.563 .458 & 10.444 .526 & 0,97 & 0,93 & 1,40 & 0,89 \\
\hline
\end{tabular}

É interessante destacar que os dados agregados do estado não permitem visualizar de forma clara as desigualdades regionais. Analisando a dinâmica populacional do Paraná, Doretto et al (2003) expõem que a população paranaense encontra-se distribuída espacialmente de forma desigual pelo território, destacandose um conjunto de municípios com maior densidade populacional e outro conjunto de municípios que já tiveram declínio ou ascensão populacional. Estes podem ser enquadrados de quatro formas distintas, quanto à sua dinâmica populacional. A primeira refere-se à região metropolitana de Curitiba, onde se encontra o maior contingente de pessoas no estado e que experimentou nas últimas décadas um grande crescimento urbano-industrial.

A segunda forma, segundo Doretto et al (2003), relaciona-se aos municípios considerados polos regionais (como Londrina, Maringá, Ponta Grossa, Cascavel, Foz do Iguaçu, Guarapuava e Umuarama), que possuem parte significativa da população e em fase de expansão decorrente da atração que exercem nas pessoas de municípios menores, que buscam melhores oportunidades de ocupação e renda.

A terceira, retrata a condição dos municípios que possuem as menores populações e se localizam em regiões rurais. Nestes municípios, a população representa uma proporção pouco expressiva em relação ao total do estado, nos quais o esvaziamento populacional ocorreu principalmente nas décadas de 1970 e 1980, fruto da mudança da base técnica da produção agropecuária. O quarto grupo de municípios, segundo os autores, caracteriza-se por ser de ocupação mais recente e em regiões com recursos naturais de menor aptidão para a agricultura, no Centro e Centro-Oeste do estado, onde se deu maior parte dos assentamentos da reforma agrária (Doretto et al, 2003).

Estas informações podem revelar que o curso da modernização agrícola caminhando no sentido de uma especialização produtiva cada vez maior, e se concentrando em áreas geográficas específicas. 
Há que se ressaltar a heterogeneidade da região Metropolitana de Curitiba evidenciada pelo fato de que, enquanto as transformações dos anos 1970 alteraram o panorama da indústria paranaense, conformando-se um moderno complexo agroindustrial, na região Metropolitana de Curitiba tem-se o nascimento da indústria metal mecânica, cujo processo prosseguiu e consolidou-se nas décadas subsequentes (Vasconcelos e Castro, 1999).

Sendo assim, por possuir mão-de-obra disponível em qualidade e quantidade, infraestrutura econômica, condições de acesso como aeroporto, rodovias, porto, custo de transportes, posição geográfica favorável ao acesso dos centros de decisões, fizeram com que a região de Curitiba $^{1}$ se transformasse num centro de atratividade para instalação de empreendimentos industriais, diferenciando-se das demais regiões do interior, que passaram a contar com fortes complexos agroindustriais ${ }^{2}$.

Nesse contexto, verifica-se o alinhamento da evolução do setor agropecuário e consolidação do agronegócio com a história econômica do estado. No decorrer do tempo o processo se consolida de modo que chega-se aos anos 2020 tendo-se o agronegócio como segmento de relevância na economia paranaense. Segundo o Sistema FAEP (2018, p.6), "o impacto do agronegócio paranaense é de cerca de $35 \%$ do seu PIB, além de dar suporte à economia da maior parte dos municípios do interior do estado". No que se refere especificamente ao setor agropecuário, sua centralidade dentro do agronegócio é apontada pela mesma fonte, ao afirmar que "embora a agropecuária represente pouco menos de $10 \%$ do PIB do Paraná (...), sem agricultura e pecuária não há agronegócio. Trata-se, portanto, de um setor vital para a economia e para a sociedade do Paraná" (SISTEMA FAEP, 2018, p. 6).

Nessa mesma linha, de acordo com Oliveira, Kureski e Santos (2020), em 2017, o PIB gerado pelo agronegócio paranaense tem relevância na economia do estado, tendo como principais produtos da agricultura a soja e o milho. Na pecuária, o Paraná destaca-se como maior exportador nacional de carne de frango e terceiro exportador de carne suína, segmentos estes, intimamente ligados à produção de soja e milho, expressando o encadeamento das atividades. Ademais, o

1 De acordo com Vasconcelos e Castro (1999), este processo ocorre especialmente na cidade industrial de Curitiba, e não de forma generalizada em todos os municípios da Região Metropolitana de Curitiba.

2 Aqui também observa-se que o desenvolvimento destes complexos não se dá de forma generalizada em todos os municípios do interior do estado. 
encadeamento da produção agropecuária se dá também com outros setores, ao alavancar as atividades fornecedoras de insumos, agroindustriais, de serviços, comercialização e distribuição dos produtos.

\section{Considerações finais}

As transformações ocorridas na agricultura brasileira também se deram no Paraná. O setor agrícola paranaense inseriu-se no processo de modernização, apresentando alterações significativas na sua estrutura produtiva. As inovações tecnológicas foram responsáveis pela mudança na pauta da produção, tendo como objetivo aprimorar sua competitividade, colocando o estado em destaque no âmbito nacional, ao apresentar resultados expressivos de sua agropecuária.

A retrospectiva acerca da evolução histórica do desenvolvimento agrícola no Paraná permitiu caracterizar a forma como o processo se configurou no estado. Primeiramente, destacou-se a descontinuidade da forma inicial de ocupação e do desenrolar das atividades econômicas no Paraná. A atividade econômica que comandava não foi capaz de criar para a sua sucessora mecanismos nos quais se pudessem gerar ocupações e rendas.

A evolução da economia agrícola do estado mostra que à perda da hegemonia da exploração comercial da cultura da erva-mate seguiu-se a emergência e consolidação da cafeicultura, que marcou a história econômica do estado. Quando o setor cafeeiro entrou em crise, incidiu fortemente sobre aspectos demográficos, na distribuição da riqueza e na força-de-trabalho.

$\mathrm{Na}$ sequência, com a inserção do Paraná no chamado processo de modernização agrícola, tem-se uma fase de alterações profundas na agricultura, com reflexos importantes sobre o rural. Na década de 1970, a intensificação no uso de máquinas, equipamentos e insumos de origem industrial, bem como a crescente incorporação de novas variedades gerou um notável crescimento agrícola. Essas mudanças tecnológicas não foram homogêneas, mas com uma tendência de difusão regional.

Nos anos 1980, a produção primária continuou o seu processo de transformação qualitativa, acentuando-se o incremento da produtividade da terra e do trabalho. Nos anos 1990, assistiu-se a um processo de perda relativa da supremacia da produção agrícola na composição do PIB estadual. Além disso, 
consolidam-se com mais clareza os produtos que dominam o setor produtivo: soja, trigo e milho.

Desse modo, o setor agrícola do estado passou por uma reorganização produtiva, apontando para um processo de melhoria da competitividade e para a consolidação de uma estrutura de produção adaptada ao ambiente econômico de maior concorrência, com resultados expressivos para a agropecuária, colocando o estado em destaque.

No decorrer do tempo, o agronegócio se consolida, tendo participação relevante na economia do estado, com o encadeamento da atividade agropecuária com o setor fornecedor de insumos, a agroindústria e serviços de comercialização e distribuição, imprimindo características próprias ao processo de desenvolvimento econômico do estado.

Finalmente, há que se apontar para impactos de todo esse processo, que extrapolam o aspecto econômico e, que, portanto, não foram abordados neste artigo: para além das questões que revelam um cenário de expansão e crescimento, há que se considerar possíveis adversidades sociais, ambientais, de saúde e de ampliação das desigualdades geradas.

\section{Referências}

ACCARINI, J. H. Economia rural e desenvolvimento - reflexões sobre o caso brasileiro. Petrópolis, Vozes, 1987.

ALBUQUERQUE, M.C. e NICOL, R. Economia agrícola - o setor primário e a evolução da economia brasileira. São Paulo, McGraw-Hill, 1987.

AMBIENTE BRASIL. Paraná - História, povoamento e colonização. Disponível em http://www.ambientebrasil.com.br. Acesso: 30.set.2005.

BRUM, A.J. Modernização da agricultura - trigo e soja. Petrópolis, Vozes, 1988.

CANCIAN, N.A. Cafeicultura paranaense 1900-1970 - estudo de conjunturas. Universidade de São Paulo. Departamento de História da Faculdade de Filosofia, Letras e Ciências Humanas. Tese de Doutorado. São Paulo, 1977.

CARNEIRO, P.T.V.M. A comercialização de feijão no Paraná 1995-2003. Universidade Estadual de Maringá. Dissertação de Mestrado em Economia. Maringá, 2004.

CAZELLA, A A . Multifuncionalidade agrícola: retórica ou trunfo para o desenvolvimento rural? In: Ciclo de Economia, VI, 2003. Anais... Francisco Beltrão, 2003.

DORETTO, M. et al. Mapeamento da pobreza no Paraná: uma situação segundo municípios e Associações de Municípios do Paraná, ano 2000. In: Congresso 


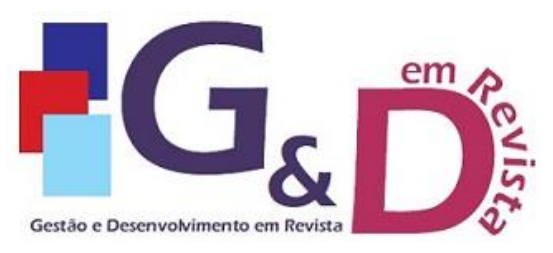

Gestão e Desenvolvimento em Revista V. 7, N. 1, jan-jun/2021, p. 15-36.

ISSN online: $2446-8738$

Artigo recebido em: 20/05/2021

Artigo aprovado em: 12/07/2021

Brasileiro de Economia, Administração e Sociologia Rural, 41, 2003. Anais... Juiz de Fora, 2003.

GRAZIANO DA SILVA, J. O desenvolvimento do capitalismo no campo brasileiro e a reforma agrária. In: STÉDILE, J.P. (org). A questão agrária hoje. Porto Alegre, UFRGS, 1994.

GONÇALVES, J.S. Mudar para manter - Pseudometamorfose da agricultura brasileira. São Paulo. CSPA/SAA, 1999.

HOFFMANN, R; NEY, M.G. Estrutura fundiária e propriedade agrícola no Brasil: grandes regiões e unidades da federação. Brasília: Ministério do Desenvolvimento Agrário, 2010.

IPARDES - Instituto Paranaense de Desenvolvimento Econômico e Social. Base de dados do Estado. Disponível em <http://www.ipardes.gov.br/imp/index.php $>$ Acesso: 12.maio.2021

MORETTO, A.C; RODRIGUES, R.L. e PARRÉ, J.L. Tendências do agronegócio no Paraná: 1980 a 1995. In: CUNHA, M.S.; SHIKIDA, P.F. e ROCHA JUNIOR, W. (orgs). Agronegócio paranaense - potencialidades e desafios. Cascavel-PR, Edunioeste, 2002.

OLIVEIRA, J.A; KURESKI, R; M.A.S. PIB do Agronegócio no Paraná. Nota Técnica Ipardes, Curitiba, n.25, Julho 2020. Curitiba, 2020.

PADIS, P. C. Formação de uma economia periférica: o caso do Paraná. São Paulo: Hucitec, 1981.

PEREIRA, L.B. O Estado e as transformações recentes da agricultura paranaense. Universidade Federal de Pernambuco. Centro de Ciências Sociais Aplicadas. Departamento de Economia. Tese de Doutorado. Recife, 1987.

PINHO, D.B. e VASCONCELLOS, M.A.S. Manual de economia. 4.ed. SP, Saraiva, 2003.

REZENDE, L.P. e PARRÉ, J.L. O desenvolvimento agrícola dos municípios paranaenses. Encontro de Economia Paranaense 2003. In: Encontro de Economia Paranaense, 2, Anais.... Maringá, 2003.

SEAB/DERAL- Secretaria da Agricultura e do Abastecimento/Departamento de Economia Rural. Perfil da agropecuária paranaense. Curitiba, 2003.

SISTEMA FAEP. Plano diretor para o agronegócio do Paraná 2019-2022. Sistema FAEP, Curitiba, 2018.

SOUZA, M. Atividades não-agrícolas e desenvolvimento rural no estado do Paraná. Universidade Estadual de Campinas. Faculdade de Engenharia Agrícola. Tese de Doutorado. Campinas, 2000.

VASCONCELOS, J.R.; CASTRO, D. Paraná: economia, finanças públicas e investimentos nos anos 90. IPEA, Brasília, Texto para Discussão n. 624, 1999. 